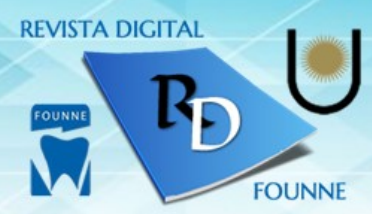

\title{
LA LECTURA EN LA FORMACIÓN ACADÉMICA
}

\section{Reflexiones en torno a la formación de lectores}

Autor: Milagros Rojo Guiñazú *

Autor de correspondencia: mrojoguinazu@odn.unne.edu.ar Av. Libertad 5450. CP 3400. Facultad de Odontología, Universidad Nacional del Nordeste. Corrientes, Argentina.

\section{Recepción: 11 de abril de 2017}

Aceptación: 04 de mayo de 2017

\section{Resumen}

El presente artículo tiene como propósito reflexionar acerca de la formación de lectores en el ámbito académico. En un recorrido de lecturas fundamentales pretendemos indagar respecto de la labor docente y de las condiciones de desarrollo lector que llevan a cabo los alumnos ingresantes en el ámbito universitario.

Con un objetivo de dilucidación de una problemática que nos afecta e involucra a todos, propongo una lectura intimista de la formación profesional de nuestros estudiantes.

Palabras Clave: lectura, formación académica, lectores, umbral, alfabetización

\section{Introducción}

Los días previos a la escritura de este artículo intenté sentarme y tomar distancia acerca de ciertos comportamientos que, en lo particular, tengo y tuve como docente; tengo y tuve como lectora.

En la actualidad reconocemos las amplias dificultades que poseen los alumnos ingresantes al Nivel Superior; y es allí cuando pensamos en la significatividad que adquieren los libros a lo largo de nuestras horas, de nuestras vidas.

¿Cuántos libros conforman mi biblioteca? ¿Cuántos libros me han acompañado a lo largo de estos años? ¿Cuánta vida y personas deambulan por nuestra memoria en relación con los libros? Hoy les propongo que me acompañen para que reflexionemos acerca de la lectura en la formación académica, para que - principalmente- pensemos en torno a la formación de lectores. 


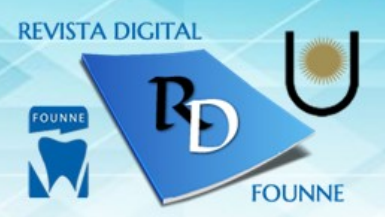

\section{Desarrollo}

Michele Petit ${ }^{1}$ sostiene que en nuestros días tenemos la impresión de que el gusto por la lectura debe abrirse camino entre lo prohibido y lo obligatorio. Todo el mundo se lamenta sobre el tema: los jóvenes no leen nada, se lee cada vez menos, ¿cómo hacer para que lean? Y podríamos interrogarnos acerca de los efectos complejos, ambivalentes, de esos discursos alarmistas y convencionales de elogio de la lectura.

Me detengo un instante y me pregunto, o más bien acompaño a los planteos de Petit, respecto de esta cuestión referente al dominio que pareciera querer ejercerse desde ciertos espacios acerca de la lectura, como la obediencia al deseo, la trasmutación de una condición de obligatoriedad a una sensación placentera.

Esta será, tal vez, la primera cuestión que atravesará nuestro pensamiento ¿cuánta imposición o sumisión lectora recorren nuestras propuestas curriculares? ¿Es un error o es un camino factible que, bien llevado, puede conducirnos a colaborar con la formación de buenos lectores?

Considero que no es un componente menor pensar en nuestra función como docentes en Comunicación (en Lengua y Literatura), como uno de los componentes esenciales en esta construcción dialógica con el otro, con nuestro otro fundamental: los alumnos. Aclaro, en particular nuestros alumnos, futuros profesionales; es decir, una dialógica que se abre paso hacia el infinito.

Delia Lerner et $\mathrm{al}^{2}$ exponen que el proceso de formación se propone incorporar activamente a los docentes al gremio de los lectores profesionales de la educación, a una comunidad cuyos integrantes frecuentan, comentan, discuten, interrelacionan, confrontan... las obras producidas en ese sector particular de la cultura escrita que está vinculado con la profesión docente y, entre ellas, los textos referidos a alfabetización.

La etapa de formación académica formal supone la introducción del alumno a un nuevo mundo. Se para en los umbrales de dos esferas que lo definen como un sujeto de fronteras: aún pertenece a una comunidad escolar (porque es ingresante, o porque aún conserva ciertas maneras de moverse propias de dicha comunidad) y ansía pertenecer a la comunidad de los estudios superiores. Pero ello le demanda atravesar un umbral y corresponderse -en todos los órdenescon los miembros de esa comunidad. 


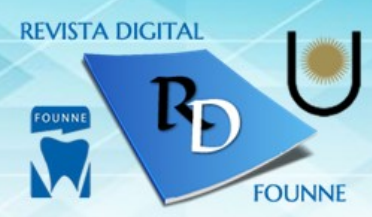

Se yuxtaponen dos esferas, y el estudiante advierte (aunque sea de manera ingenua) que las discusiones y los temas son otros, que su posicionamiento frente al texto es (o debería ser) otro. Pero, en muchas ocasiones los docentes los ponemos en ese rol -incómodo si lo hay para un ser entre umbrales- de lectores académicos, sin siquiera haberlos preparado o acompañado en ese transitar.

Esta será, tal vez, la segunda cuestión sobre la que haremos hincapié ¿reconocemos a los alumnos del nivel superior como aspirantes para integrar una nueva esfera? ¿Los conducimos fehacientemente para que ellos transiten el paso de un umbral a otro de manera consciente, efectiva, formativa?

Creo que esas expresiones a las que refería Petit son un clásico en las discusiones entre los docentes de todos los tiempos y de todos los niveles. Es mucho más sencillo pensar que el problema está en los otros: los alumnos no leen, los alumnos cada vez leen menos; en lugar de revisar en nuestras prácticas las propuestas que llevamos a nuestras asignaturas y en lugar de indagar si nosotros somos lectores (no lectores de la palabra, sino lectores en serio, los del libro en mano página tras página).

Pensar en la lectura como práctica social nos remite, por lo menos a mí personalmente, a esos momentos en los que el placer de la lectura me transportaba hacia otro mundo, otro universo, el de las ficciones que envolvían el aire y eclipsaban al reloj deteniéndose eternamente.

Me detengo un breve instante y me cuestiono: ¿Qué nos sucede cuando comenzamos las etapas de escolarización? ¿Esa magia se traslada con nosotros? ¿Respiramos ese aire místico en la escuela? ¿Qué sucede entre la escolarización y el placer de la lectura? ¿Nos transformamos en lectores? ¿Mueren los lectores? Qué paradoja...

Aquí llegamos a uno de los puntos esenciales de este artículo: el pensarnos como lectores, el pensar a nuestros alumnos como lectores.

Mucho antes de pensar a la lectura como parte de mi formación profesional ya me había transformado en lectora, una lectora ingenua -si se quiere-. Es decir, al ingreso a la educación superior ese camino lector iniciado con anterioridad comenzaría a tomar cuerpo, a adquirir una cierta forma en correlación con los procesos de enseñanza y aprendizaje por los que iba transitando. 


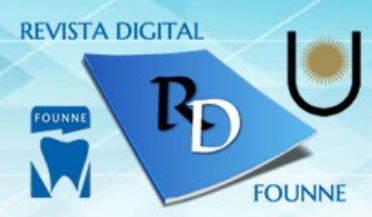

Con nuestros alumnos nos sucede algo similar, puesto que ellos ingresan a los espacios de formación superior con lecturas y prácticas de lecturas aprehendidas; por lo que, en algunos casos debemos acompañarlos, guiarlos, orientarlos para que transiten los caminos de la lectura académica, la que gradualmente se va complejizando y exigiendo ciertas producciones que denoten los procesos realizados. En otros términos, los acompañamos a pasar el umbral hacia la nueva esfera que los contendrá y que representa una antesala para la esfera superior que involucra su ser docentes.

Desde esa perspectiva lo conciben Lerner et $\mathrm{al}^{3}$, puesto que son, justamente, las situaciones de doble conceptualización [las que] brindan oportunidades de compartir la lectura y la escritura en el espacio de formación y, en ese sentido, contribuyen a la conformación de una comunidad de lectores y escritores -comunidad que se consolidará y ampliará a través de muchas otras instancias-.

En correlación con las prácticas de lectura en el ámbito académico, Paula Carlino ${ }^{4}$ fundamenta la complejidad y la fuerza del concepto, alfabetización académica, al poner de manifiesto que los modos de leer y escribir son específicos de cada ámbito. Advierte contra la tendencia a considerar que la alfabetización es una habilidad básica, que se logra de una vez y para siempre; cuestiona la idea de que aprender a producir e interpretar lenguaje escrito es un asunto concluido al ingresar en la educación superior; objeta que la adquisición de la lengua y la escritura se completen en algún momento. Por el contrario, la diversidad de temas, clases de textos, propósitos, destinatarios, reflexión implicada y contextos en los que se lee y escribe plantean siempre en quien se inicia en ellos nuevos desafíos y exigen continuar aprendiendo a leer y escribir.

El camino de la formación, tal como lo plantea Carlino ${ }^{5}$, es un proceso continuo de avance, de aprendizaje, de revisión y reinicio. Constantemente estamos aprendiendo a leer y a escribir una vez que comenzamos a hacerlo. Las prácticas se complejizan de acuerdo con el nivel que transitamos, pero el aprendizaje nunca se completa.

Así, podríamos preguntarnos: ¿a quién le compete ocuparse de estas cuestiones problemáticas de la lectura y la escritura en la educación superior?, ¿los profesores logran reconocer la lectura como un objeto de enseñanza, al tiempo que un medio para adquirir conocimientos?, ¿qué 


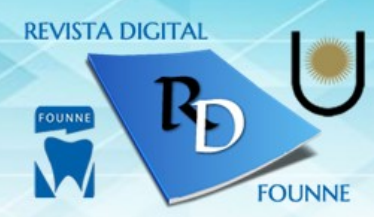

condiciones y situaciones didácticas deberían cumplirse para la formación de lectores autónomos?, ¿el profesor conoce o advierte la complejidad de los procesos involucrados en la lectura de un texto académico superior?, ¿es consciente del uso de estrategias cognitivas en su propio proceso como lector?, ¿reconoce en los estudiantes la construcción de sentido en el abordaje de un texto escrito?

Creo que lo importante es saber que la lectura y la construcción de un lector formado en el ámbito académico, son dos líneas que en algún momento, inexorablemente, deben tocarse y atravesarse en el placer y goce del acto mismo, del contacto con el objeto libro y con esa magia que envuelve a sus páginas y nos transporta a otros tiempos, a otros mundos.

Erróneo sería creer que un buen lector académico lo es, sin antes no haber sido un buen lector en su cotidianeidad. Únicamente desde ese espacio podemos pensar en la lectura como una práctica viva que permite compartir emociones con los colegas, conocer e identificarse con autores y personajes, pero también profundizar temas y confrontar la propia práctica con otras.

Entonces nos preguntamos, ¿Qué es un buen lector? ¿El docente construye buenos lectores? ¿El lector nace o se hace, parafraseando a Simone de Beauvoir ${ }^{6}$ ?

Necesariamente todo es cierto y falso a la vez. La existencia de un buen lector es una realidad, y es concebible desde múltiples dimensiones: uno puede ser buen lector porque lee mucho, porque lee buenos textos, porque toma buenas decisiones como lector, porque es crítico de sus propios recorridos como lector, entre otras razones.

Asimismo, puede suceder que uno decida hacerse lector, o que los senderos y personas con las que uno convive lo conduzcan intencionalmente hacia ese cauce.

Todo ello no resta valor a la labor docente (al docente de todos los niveles), puesto que la influencia - positiva o negativa- en muchos casos es determinante para el corolario de esa “construcción”. La formación de lectores no se inicia en el nivel superior, la formación comienza cuando la gestación se inicia.

Como especialista en Lectura, pero fundamentalmente como madre y lectora, sé que no existe vínculo con los libros que no se construya desde el día cero de un niño. El niño al que su madre le susurró historias, le cantó historias o que leyó en voz alta sus lecturas cotidianas durante la 


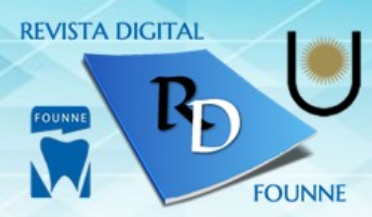

etapa de gestación, vive la lectura desde un lugar de placer, es el remanso que le rememora inconscientemente su vida en el vientre.

Es un compromiso de los formadores de formadores asumir la transcendencia de nuestro rol en esta formación de lectores; puesto que nuestro hacer o deshacer serán determinantes para sus desarrollos. Qué se lee, cómo se lo lee, desde qué lugar se lee... son construcciones que delinean el ser docente y condicionan a los alumnos que intentan construir su mundo lector desde esos espacios, espacios que arbitrariamente escoge y debe hacerse responsable el profesor.

Nos detendremos unos segundos para pensar en nuestras programaciones de cátedras. ¿Qué legitimación de la lectura subyace detrás de cada palabra, de cada selección, de cada obra que se nombra y de todas las que quedan inevitablemente silenciadas?

La arbitrariedad en nuestros recortes y opciones no son un error, son solamente eso, una propuesta de abordaje de la lectura; conjuntamente, la selección de cierta metodología de trabajo tampoco lo es. No obstante, debemos saber y hacérselo saber a nuestros estudiantes que es un modo de leer, no el único, no el mejor, sino el que nosotros escogimos. Asimismo, que las selecciones de textos responden a los mismos principios, fueron "elecciones", que conviven con nuestros gustos y pareceres.

Como la novela que es una urdimbre de relaciones según la define Oscar Tacca ${ }^{7}$ en Instancias de la novela, el entramado de una programación de cátedra es una urdimbre de relaciones que establece el profesor entre sus inclinaciones, expectativas y objetivos. Al igual que los alumnos, muchas veces los docentes nos paramos en los umbrales - de manera constante o sólo un instante- y pensamos desde el canon y desde fuera del mismo.

Es interesante pensar o reflexionar acerca de estas cuestiones, porque nos obligan a rever desde su médula a nuestro quehacer como formadores. Una reflexión necesaria, por cierto, para no empantanarnos en un discurso eterno.

Finalmente, quiero hacer anclaje en la noción de formador de lectores que formarán lectores.

En agosto de 2008 en el artículo "Volver a los Clásicos" publicado en la Revista La lectura ${ }^{8}$ escribía que "la lectura es un vínculo que establece un ser con el alma del escritor, con ese creador e inventor de ficciones que acompañan nuestro camino." 


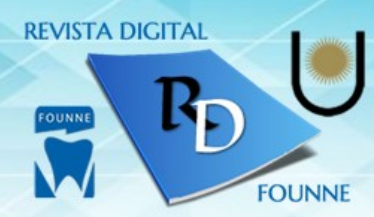

Tanto en ese momento como ahora, y tal como lo vengo desarrollando desde el principio, pienso acerca de la correspondencia existente entre la lectura y la educación, entre la lectura y la profesión, con el placer, la obligación, con ese otro mundo.

Sigo deteniéndome y observando el etéreo lazo que los jóvenes poseen con el libro; y no dejo de evidenciar una relación de compromiso asociada con el ámbito escolar. Allí me detengo un instante y me pregunto, ¿cuántos de esos jóvenes fueron bebés / niños lectores?

Inevitablemente el vínculo que se tiene con un texto se construye -como cualquier otro- sobre la base del tiempo, el deseo, la voluntad, la dedicación y el placer. Propiciamos las relaciones que nos generan goce, y si en nuestra débil memoria avizoramos vivencias gratificantes asociadas con el instante de la lectura, ciertamente esa será una relación que no querremos abandonar.

Como formadores de lectores que formarán lectores ¿nos reconocemos como lectores, es decir, nosotros realmente estamos en esa categoría? ¿Leemos? ¿Cuánto leemos? ¿Por qué leemos? ¿Cuándo leemos?

Y ¿cómo somos como formadores? ¿Generamos el espacio del encuentro con el libro o ya lo ubicamos al alumno en correspondencia de un cuerpo crítico "indicado" para su análisis o abordaje?

Hay mucha voluntad y deseo en buena parte de los formadores, porque queremos formar lectores inteligentes, capaces -inclusive- de leer en los textos que les ofrecemos cuestiones que a veces nosotros no llegamos a descubrir o ver aún. Y detrás de ese deseo, seguramente habrá un error -o muchos-, puesto que el camino de la docencia es un continuo trayecto de aprendizajes, de descubrimientos.

Sin embargo, no es concebible -al menos desde mi perspectiva- poder ser formadores de lectores sin que los docentes seamos primero lectores y sin que se advierta el placer que sentimos por la lectura, por el contacto con los libros.

El eterno dilema "la obligación" versus "el placer" colapsa. No existe posible formación que no nazca desde nuestro centro más íntimo, no podemos enseñar aquello que no amamos... no 


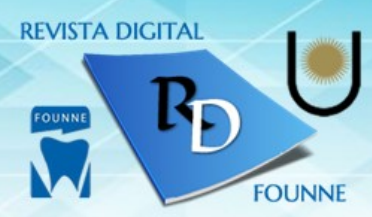

podemos transmitir el placer de la lectura cuando para nosotros no es un placer leer, cuando nosotros no leemos.

Este quizás sea el punto de contacto con los planteos iniciales de Petit...

Los jóvenes no leen nada, se lee cada vez menos, ¿cómo hacer para que lean?

Tal vez no lean o lean menos por la sencilla razón de que no observan a sus docentes hacerlo, o porque la no lectura de los docentes hace que las propuestas que ellos les ofrecen no sean motivadores.

Con ello no quiero responsabilizar a los formadores de la no lectura de sus alumnos, sino que quiero que este espacio nos permita reflexionar y revisar nuestras propias prácticas docentes, las de todos; para mejorarlas, para volverlas a vivir como creo que hace un tiempo atrás la mayoría lo vivía, como una experiencia espiritual, rodeada de misterio y encanto, una fascinación oculta detrás de cada página, un encuentro jubiloso e íntimo con el libro.

\section{Conclusiones}

Así, con este breve artículo deseo que reflexionemos acerca de nuestra labor y de nuestros propios vínculos con "el libro". Creo fervientemente en el arrasador poder que posee un libro en la vida de una persona. Se genera un vínculo imposible de describir, imposible de asociar con otro.

Vuelven a mi memoria los instantes en los que mi vida, como creo que les pasa a la mayoría de ustedes, estuvo pensada desde los libros... y asevero que no puedo concebir mi existencia sin ellos. Mi formación como lectora no sólo estuvo vinculada con la formación académica, sino que fue una experiencia que se hizo carne en mí desde pequeña.

\section{Bibliografía}

1. Petit, M. Lecturas: del espacio íntimo al espacio público. Ed. Fondo de Cultura Económica; 2001.

2. Lerner, D.; Stella, P.; Torres, M. Formación docente en lectura y escritura. Recorridos didácticos. Ed. Paidós; 2009. 
3. Lerner, D.; Stella, P.; Torres, M. Formación docente en lectura y escritura. Recorridos didácticos. Ed. Paidós; 2009.

4. Carlino, P. Escribir, leer y aprender en la Universidad. Una introducción a la alfabetización académica. Ed. Universidad de Buenos Aires; 2009.

5. Carlino, P. Escribir, leer y aprender en la Universidad. Una introducción a la alfabetización académica. Ed. Universidad de Buenos Aires; 2009.

6. Beauvoir, S. de. El segundo sexo. Ed. Sudamericana; 1999.

7. Tacca, O. Instancias de la novela. Ed. Marymar; 1980.

Rojo Guiñazú, M. Volver a los clásicos. Revista La Lectura, año 10, No 11. agosto 2008. ISSN 1851-9318 http://aal.idoneos.com 